\title{
A Construção de Políticas Ambientais Internacionais: 0 caso do Mercosul ${ }^{1}$
}

The Construction of International Environmental Policies: The case of Mercosur

Ludmila A. Culpi ${ }^{2}$

\section{RESUMO}

O objetivo do presente artigo é apresentar uma análise sobre a evolução dos regimes internacionais de defesa do meio-ambiente a respeito da redução das práticas de consumo não sustentáveis, com ênfase sobre as políticas criadas no Mercosul. o problema que o artigo pretende responder é de que forma ocorre a formação de uma cultura internacional de defesa do meio-ambiente no Mercosul, a partir da institucionalização de regimes ambientais regionais que visam regulamentar a temática do desenvolvimento sustentável, atribuindo responsabilidade ao consumo pela crise ambiental.

Palavras-chave: Mercosul; Políticas Ambientais Internacionais; Desenvolvimento Sustentável.

\begin{abstract}
The objective of this paper is to present an analysis of the evolution of international regimes of the defense of the environment regarding reducing unsustainable consumption practices, with emphasis on policies created in Mercosur. The problem that the article intends to answer is how occurs the formation of an international culture of the defense of the environment in Mercosur, from the institutionalization of regional environmental regimes that seek to regulate the theme of sustainable development, assigning responsibility to the consumption for the environmental crisis.
\end{abstract}

Keywords: Mercosur; International Environmental Policies; Sustainable Development.

\section{Introdução}

A problemática sobre a devastação do meio-ambiente foi defendida com mais vigor na sociedade internacional a partir da década de 1970, quando os grupos ambientalistas passaram a pressionar o governo para oferecer maior proteção ao meioambiente. A consciência ecológica tem despertado debates acalorados e foi incluída definitivamente na agenda global a partir das Conferências Internacionais, como a ECO 92, que reuniu os Estados e representantes da sociedade civil para discutir soluções conjuntas e regulações ao uso excessivo de recursos naturais (COSTA e TEODÓSIO, 2011).

\footnotetext{
${ }^{1}$ Artigo recebido em 11 de março de 2014 e aprovado em 31 de março de 2014.

${ }^{2}$ Doutoranda em Políticas Públicas pela Universidade Federal do Paraná, Mestre em Ciência Política pela Universidade Federal do Paraná, Professora de Relações Internacionais e Ciência Política do Centro Universitário Internacional Uninter.
}

Conjuntura Global, Vol.3, n.1, jan./mar., 2014, p. 13-20. 
Considera-se fundamental harmonizar o paradoxo entre a sociedade de consumo moderna e o meio-ambiente. Costa e Teodósio (2011) colocam que existe um legítimo impasse entre meio ambiente e desenvolvimento econômico, à medida que não se definem patamares sustentáveis nas relações de consumo e produção.

Um dos processos mais relevantes no âmbito da proteção ao meio-ambiente é a integração regional, pois os interesses estatais buscam uma convergência. Além disso, o interesse ambiental se torna uma preocupação conjunta, com vistas a aliar as pretensões econômicas com as sociais. Deste modo, o objetivo geral do artigo é estudar a atual situação das políticas de sustentabilidade ambiental no Mercosul com vistas a verificar a viabilidade de se atingir uma convergência e uma redução dos danos ao meio-ambiente na região do Cone Sul.

\section{O desenvolvimento econômico e a crise ambiental}

As nações mais avançadas realizaram suas revoluções industriais sem maiores preocupações com o impacto desses modelos de crescimento sob os ecossistemas. Contudo, a partir da década de 1980, verifica-se um crescimento da percepção social dos efeitos do consumo sobre o meio-ambiente, concretizadas nos Encontros ocorridos entre os países (SOUZA, 1994).

O teórico Durning (1992) suscita uma reflexão, ao desenvolver uma crítica ao padrão de consumo conspícuo da sociedade contemporânea o qual o autor considera o responsável pelos efeitos perversos causados ao meio-ambiente. Durning (1992) aponta o papel do consumo na destruição dos ecossistemas, ao destacar que à medida que os indivíduos ascendem socialmente atingindo o status de consumidor, o seu impacto sobre o meio-ambiente aumenta, tendo em conta que passam a consumir novidades.

Uma das constatações mais relevantes do texto de Durning (1992) é de que a influência do consumo tem afligido mais as regiões povoadas pelas classes mais baixas, em função de serem sedes de indústrias que na busca de custos de produção mais baixos, destroem o planeta e exaurem os recursos dessas nações menos favorecidas.

Quanto às perspectivas de redução da devastação, Durning (1992) destaca que embora o uso de combustíveis fósseis tenha se estabilizado em 1970 em função da volatilidade dos preços, seriam necessárias alterações em termos tecnológicos, o que exigiria que houvesse uma redução drástica no padrão de consumo da sociedade. Isso

Conjuntura Global, Vol.3, n.1, jan./mar., 2014, p. 13-20. 
obviamente não é desejado pelas grandes empresas, que observariam a redução dos seus lucros.

Constata-se a partir de 1970 que o estilo de vida dos países ricos passou a ser repetido pelos países de menor renda, o que promovia a reprodução de um consumo cada vez menos sustentável. Os Estados que percebem a relevância social do consumo, o colocam como objeto de política e uma variável estratégica relevante. Porém, quanto ao impacto do consumo sobre o meio-ambiente, embora seja uma questão central na pauta internacional, poucos são os compromissos firmados.

\section{Respostas Institucionais para o Problema Ambiental}

Revela-se a urgência em compatibilizar o crescimento econômico com a sustentabilidade e as dificuldades em se conseguir comprometimento dos Estados e das grandes empresas em relação ao tema, o que motivou a elaboração de um relatório que buscou introduzir o conceito de sustentabilidade. O Relatório Brundltand, formulado em 1987, popularizou o conceito de sustentabilidade e atentou para a necessidade de definição de estratégias de longo prazo que combatessem as causas dos problemas ambientais (SOUZA, 1994).

No que tange ao debate sobre desenvolvimento sustentável, um marco fundamental foi a Conferência das Nações Unidas sobre o meio ambiente humano, realizada em Estocolmo em 1972, pois foi a partir deste encontro que se associa a qualidade de vida ao desenvolvimento (SOUZA, 1994). Por sua vez, a Conferência de Cocoyoc (1974), que tratou dos Modelos de utilização de recursos, meio ambiente e estratégias de desenvolvimento representou um avanço ao incrementar ao debate o papel dos Estados industrializados na expansão do problema ambiental.

Na Conferência das Nações Unidas sobre Meio-Ambiente realizada no Rio de Janeiro em 1992, foi formulada a "Agenda 21", que definiu um novo paradigma sobre o meio-ambiente, contribuindo para a gestão de políticas públicas dos Estados com vistas a criar um novo modelo de desenvolvimento em harmonia com a proteção do meioambiente. Cada Estado possuía autonomia pra definir a sua Agenda 21, que no Brasil foi estabelecida em 1997 pela Comissão de Políticas de Desenvolvimento Sustentável (QUEIROZ, 2005). Deve-se destacar que a autonomia concedida aos Estados na Agenda 21 para legislar sobre as questões de sustentabilidade demonstra a ineficácia das

Conjuntura Global, Vol.3, n.1, jan./mar., 2014, p. 13-20. 
organizações internacionais em garantir o comprometimento de todos os Estados na questão, pois esses resistem em transferir soberania às organizações capacitadas para tratar da problemática (QUEIROZ, 2005). Isso se comprova na última Conferência do Meio-Ambiente da ONU realizada em 2012 no Rio de Janeiro, cujos documentos produzidos carecem de ações concretas e refletem a falta de compromisso com a redução das práticas de produção e consumo danosas ao meio-ambiente.

Em 2002, realizou-se a Cúpula Mundial sobre Desenvolvimento Sustentável, em Johanesburgo, a qual promoveu a análise do consumo e revelou-se que a questão não havia tido progresso, devido à falta de políticas que promovessem o consumo sustentável. O PNUMA (Programa das Nações Unidas para o Meio-Ambiente) apontou a necessidade de se estabelecer um novo encontro, que culminou no Processo de Marrakesh de 2002, que tinha como objetivo garantir a aplicabilidade do conceito de Produção e Consumo Sustentáveis (PCS). Esse documento reivindica que os Estados da ONU desenvolvam planos de ações para incentivar padrões de produção e consumo sustentáveis. No Brasil, apenas em 2008 foi criado um Comitê Gestor Nacional de Produção e Consumo Sustentáveis, tendo o propósito de buscar padrões de consumo menos prejudiciais (QUEIROZ, 2005).

\section{Perspectivas teóricas sobre a questão ambiental}

Quanto à perspectiva teórica das relações internacionais sobre a gestão coletiva do meio-ambiente colocam-se três abordagens, quais sejam: os regimes internacionais, a governança global e as respostas institucionais. Conforme seu idealizador Stephen Krasner, os regimes internacionais referem-se à construção de normas, princípios e regras sobre uma temática comum, que envolvem Estados e demais atores envolvidos. Já a governança global, estabelecida por Rosenau, é mais abrangente do que o conceito anterior por incluir todos os regimes existentes, nas mais diferentes questões que têm impacto sobre o meio-ambiente. Por fim, as respostas organizacionais tratam das organizações internacionais criadas para buscar as soluções para a crise ambiental (BARROS-PLATIAU, SCHLEICHER, VARELLA, 2004).

Deste modo, as respostas institucionais relacionam-se aos esforços dos Estados em criar instituições multilaterais, dentre as quais se destacam quatro: o Programa das Nações Unidas para o Meio Ambiente (Pnuma); a Comissão de Desenvolvimento 
Sustentável (CDS) e a Organização das Nações Unidas para o Meio Ambiente (Onuma); as respostas regionais e as iniciativas das Organizações da Sociedade Civil (OCS) (BARROS-PLATIAU, SCHLEICHER, VARELLA, 2004).

Segundo Barros Platiau, Schleicher e Varella (2004), o Pnuma foi criado após a Conferência de Estocolmo, porém demonstrou o impasse entre os Estados defensores da criação de uma organização sobre meio-ambiente dentro do âmbito da ONU e os contrários. Assim, dado o fracasso da criação do Onuma relacionado à desconfiança da maioria dos Estados em relação à criação de uma organização com objetivos ambientais relacionados aos países industrializados, estabeleceu-se apenas um programa. 0 Pnuma nunca desempenhou um papel relevante no cenário internacional, pois foi utilizado como fórum de debate dos países do Sul que reclamavam uma maior inserção nas relações internacionais e acabou esvaziado pelos países mais desenvolvidos. No final da década de 1990, em função dos resultados insatisfatórios da Rio-92, o debate sobre a criação do Onuma foi resgatado, sob uma proposta de vinculação a OMC. O Brasil e outros países emergentes defenderam o fortalecimento da Comissão sobre Desenvolvimento Sustentável (CDS) em substituição a criação do Onuma, que ficou apenas no papel.

As respostas regionais, foco deste artigo, e as iniciativas da sociedade civil são compreendidas como uma das soluções apontadas mais eficazes para superar as dificuldades da cooperação internacional no âmbito ambiental, tendo em conta que a questão regional foi priorizada em outros campos que obtiveram êxito. Na América do Sul, encontrou-se respaldo em iniciativas como a Organização do Tratado de Cooperação Amazônica e em documentos produzidos dentro da ALALC e do Mercosul. Porém, a instabilidade política da região e a fragilidade institucional transformam o atendimento de questões sociais em um objetivo de difícil implementação (BARROS-PLATIAU, SCHLEICHER, VARELLA, 2004).

Na próxima seção será tratada a resposta regional à questão do meio-ambiente dada pelos países do Cone Sul. Para tanto, serão estudados os esforços de harmonização das políticas de sustentabilidade dos países participantes do Mercosul e os obstáculos a adoção de politicas de consumo sustentável.

4. Políticas de consumo sustentável no Mercosul: impasses e desafios 
O Mercosul, um projeto de cooperação regional entre Brasil, Argentina, Uruguai e Paraguai foi estabelecido em 1991 pelo Tratado de Assunção, buscando a liberalização comercial da área e o avanço para uma integração e coordenação em áreas políticas, como a ambiental (VAZ, 2002). No ano de 2012 houve a suspensão do Paraguai do bloco, justificada pelo não reconhecimento do golpe de Estado que derrubou o então presidente Fernando Lugo. Além disso, houve a entrada da Venezuela no Mercosul em 2013, a qual era freada pela negação do Paraguai em incluir o Estado venezuelano no bloco.

No momento de criação do bloco, na década de 1990, os Estados estavam promovendo uma abertura de seus mercados, a partir da adoção da perspectiva neoliberal, a qual defende uma adaptação das economias aos postulados do Consenso de Washington, associados à liberalização completa da economia e à redução do papel do Estado na mesma. Deste modo, a preocupação era com a liberalização e o consequente desenvolvimento econômico que se acreditava que esta promoveria, o que coloca a questão do meio-ambiente em segundo plano (VAZ, 2002).

No Tratado de Assunção, há uma previsão em relação à proteção ambiental, porém bastante superficial, pois não trata da necessidade de normatização conjunta. Vale destacar que os países que fazem parte do processo são países em desenvolvimento que buscam crescimento econômico e em muitos momentos visualizam a questão ambiental como um obstáculo ao progresso econômico (CHEREM, 2003).

O Mercosul conta ainda com um Subgrupo de Trabalho do Meio-Ambiente, criado em 1995, vinculado ao Grupo Mercado Comum. O Grupo Mercado Comum é o organismo executivo do bloco e é o principal órgão de implementação dos objetivos do Mercosul e de supervisão do seu funcionamento. É subordinado ao Conselho do Mercado Comum e as resoluções que adota são obrigatórias para todos os membros do bloco, porém não há previsão de mecanismos de sanção para os países que não cumpram as normas adotadas, o que colabora para sua ineficácia. Observa-se então, que há uma tentativa de incluir a questão ambiental nos níveis mais altos de discussão. Contudo, o tratamento da problemática ambiental é atendido apenas quando impacta sobre a liberalização comercial e a competitividade entre os membros (SCHETJTMAN; TCHINTIAN, 2003).

No que tange as políticas ambientais conjuntas no Mercosul, poucas são as ações concretas em prol de uma mudança nos padrões de produção e consumo das sociedades envolvidas. Segundo Queiroz (2005), a primeira iniciativa tomada no sentido de

Conjuntura Global, Vol.3, n.1, jan./mar., 2014, p. 13-20. 
equilibrar as práticas de comércio com o meio-ambiente foi uma resolução de 1994, a qual definia as diretrizes gerais da política ambiental dos países membros.

No ano de 2001 foi consubstanciado em Assunção o Acordo Marco sobe MeioAmbiente do Mercosul. De antemão, coloca-se que a própria natureza do tratado impede sua eficácia, por se tratar apenas de uma agenda com objetivos a serem alcançados, sem adequação automática aos ordenamentos jurídicos nacionais, em função do respeito à soberania de cada Estado. Portanto, o Acordo não provoca efeitos imediatos sobre as legislações de sustentabilidade, não avançando para a harmonização de políticas.

Como analisado nesse artigo, o Mercosul não obteve êxito na construção de mecanismos de gestão coletiva dos recursos naturais, dentre os quais se destaca o Aquífero Guarani. 0 fracasso da produção de um Protocolo Ambiental demonstra a falta de vontade política dos Estados membros e a ênfase da questão ambiental relacionada à perda de competitividade industrial e comercial e não como uma preocupação legítima. O Acordo Marco Sobre Meio Ambiente revela uma declaração de boas intenções, com muita retórica e pouco conteúdo e compromissos. Deste modo, os Estados do Cone Sul negam uma legislação sobre meio-ambiente que possa incentivar um protecionismo comercial.

\section{Considerações finais}

No presente artigo, visou-se demonstrar os impactos da explosão do consumo sob os ecossistemas, sobretudo, dos países menos avançados, que arcam com os custos da manutenção dos padrões de consumo dos países desenvolvidos. Na sequência foram apontados os desenvolvimentos dos regimes ambientais internacionais, a partir da preocupação com os efeitos do desenvolvimento econômico sobre o meio-ambiente. Nesse sentido, uma das respostas institucionais oferecidas pelos Estados com vistas a criar políticas de racionalização do consumo são as iniciativas regionais, como as formuladas no âmbito do processo de integração regional do Mercosul. Assim, o objetivo central do artigo foi analisar as políticas de consumo sustentável produzidas no seio do Mercosul.

Observou-se que no Mercosul há pouco avanço na questão da coordenação de políticas de produção e consumo sustentáveis, pois os documentos produzidos não representam constrangimentos a ação dos Estados, que mantém práticas de violação do

Conjuntura Global, Vol.3, n.1, jan./mar., 2014, p. 13-20. 
meio-ambiente. Nesse sentido, uma das justificativas para a dificuldade em promover políticas sustentáveis no Mercosul é que este envolve países em processos de desenvolvimento, os quais não visualizam a questão do meio-ambiente como uma prioridade em suas políticas nacionais.

\section{REFERÊNCIAS BIBLIOGRÁFICAS}

BARROS-PLATIAU, Ana Flávia; VARELLA, Marcelo Dias; SCHLEICHER, Rafael T. Meio ambiente e Relações Internacionais: perspectivas teóricas, respostas institucionais e novas dimensões de debate. Rev. bras. polít. int., Dez, vol.47, no.2, p.100-130, 2004.

CHEREM, T. A proteção do meio ambiente nas dimensões do Mercosul. Novos Estudos Jurídicos. V. 8, no.1, 123-143, 2003.

COSTA, D.; TEODóSIO. A. Desenvolvimento sustentável, consumo e cidadania: um estudo sobre a (des)articulação da comunicação de organizações da sociedade civil, do estado e das empresas. RAM, Rev. Adm. Mackenzie (Online), 2011, vol.12, n.3, pp. 114$145,2001$.

DURNING, A. How much is enough? The consumer society and the future of the earth. Nova York: W. W. Norton \& Company [Capítulo 4], 1992.

MERCOSUL/ CMC/DEC no.02/01. Acordo Quadro Regional Sobre Meio-Ambiente. Disponível em: http://www.mercosur.int/msweb/Normas/normas_web/Decisiones/PT/Dec_002_001_ Acordo\%20Meio\%20Ambiente_MCS_Ata\%201_01.PDF. Acesso em 16 de agosto de 2013.

QUEIROZ, Fábio. Meio ambiente e comércio na agenda internacional: a questão ambiental nas negociações da $\mathrm{OMC}$ e dos blocos econômicos regionais. Ambient. soc., vol.8, no.2, Campinas, jul/dez, 2005.

SCHEJTMA, Lorena; TCHINTIAN, Carolina. Mercosur Sustentable: Potencialidades y falencias analizadas en la perspectiva del caso del Sistema Acuífero Guaraní. Presentado ante el VI Congreso Nacional de Ciencia Política Universidad Nacional de Rosario, noviembre, 2003.

SOUZA, André. Meio Ambiente e Desenvolvimento Sustentável: uma reflexão crítica. Paper do Naea, 45, agosto, São Paulo, 1994.

TOGASHI, H. A Sustentabilidade e o Cosmpopolitismo das Relações de Consumo na Sociedade Moderna: problematização de um paradoxo e perspectivas para o novo século. Vox Juris. ano 2, v. 2, n. 1, pág. 293-319, 2009.

VAZ, Alcides Costa. Cooperação, integração e processo negociador: a construção do Mercosul. Brasília: Funag/Ibri, 308 p, 2002.

Conjuntura Global, Vol.3, n.1, jan./mar., 2014, p. 13-20. 